\title{
General practitioners' views on key factors affecting their desired income: A principal component analysis approach
}

\author{
Mohsen Bayati ${ }^{1}$, Arash Rashidian ${ }^{1 *}$, Ali Akbari Sari ${ }^{1}$, Sara Emamgholipour ${ }^{1}$
}

Received: 20 Apr 2016

Published: 27 Jul 2017

\begin{abstract}
Background: Based on the target income hypothesis, the economic behavior of physicians is mainly affected by their target income. This study aimed at designing an instrument to explain how general practitioners (GPs) set their desired income.

Methods: A self-administered questionnaire of affecting factors on GPs' target income was extracted from literature reviews and a small qualitative study. Respondents were 666 GPs who completed the questionnaire (response rate $=52 \%$ ) during 2 seasonal congresses of Iranian GPs. The principal component analysis (PCA) with varimax rotation was used to classify the variables and data reduction. Sample adequacy test, sphericity test, eigenvalues of components, and scree plot were evaluated for PCA. Cronbach's alpha was also checked to assess the internal consistency of the principal components.

Results: The results of the KMO measure of sampling adequacy (0.657) and Bartlett's test of sphericity $(809.05$, p $<0.001)$ revealed that the collected data were suitable for PCA.

Based on the scree plot pattern and eigenvalues greater than 1, 6 components including perceived comparative income, importance of responsiveness to patients, perceived socioeconomic status, economic expectations, socioeconomic status of paternal family, and provision of luxury services were selected, which explained $65.19 \%$ of the total variance. Finally, only those with a Cronbach's alpha value higher than 0.6 were considered reliable (the first 4 components).

Conclusion: Based on the target income hypothesis, physicians' desired level of income would affect their behavior. Our developed instrument and its mentioned components can be used in future studies related to GPs' behavior, especially those studies related to the economic aspects of GPs' behavior. It also helps formulate a better payment mechanism for primary care providers.
\end{abstract}

Keywords: General practitioner, Behavioral economics, Healthcare economics and organizations, Target income hypothesis, Principal component analysis

Copyright $₫$ Iran University of Medical Sciences

Cite this article as: Bayati M, Rashidian A, Akbari Sari A, Emamgholipour S. General practitioners' views on key factors affecting their desired income: A principal component analysis approach. Med J Islam Repub Iran. 2017 (27 Jul);31:41. https://doi.org/10.14196/mjiri.31.41

\section{Introduction}

Physicians play a pivotal role in any health system. They are the main health care providers and the decisions they make regarding the diagnosis and treatment of patients affect resource flow and the volume of health care costs $(1,2)$

Moreover, the decisions that physicians make stem from their economic and ethical preferences (3). This issue has been assessed using several different approaches to a physician's behavior. Some approaches mainly focus on the

Corresponding author: Dr Arash Rashidian, arash.rashidian@gmail

1. Department of Health Management and Economics, School of Public Health, Tehran University of Medical Sciences, Tehran, Iran. financial interests of the physicians. For example, in the profit maximization model, income is the main factor that affects a physician's behavior $(4,5)$. However, other approaches such as the charity hypothesis (3) or the medical ethics approach (6) emphasize the social role of the physician, and state that physicians differ from other firms, and have different goals in mind.

In an agreed approach among health economists, known as the target income hypothesis, physicians' behavior is

$\uparrow$ What is "already known" in this topic:

According to some health economists, physicians, as the main providers of health care services, behave based on their desired income. In this regard, a key unanswered conceptual question is how physicians set their income targets.

$\rightarrow$ What this article adds:

A valid and reliable instrument was developed to assess the main factors related to physicians' economic behavior. The developed questionnaire and the main extracted principal components can be used for a better understanding of how physicians set their target income. 
mainly affected by their desired income (7-10). If a physician's actual income falls below their desired income level, they begin making a number of economic decisions to restore their income to its desired level. These decisions may include actions like setting higher prices for services, increasing working hours, and seeing a greater number of patients $(2,11,12)$. On the other hand, if their actual income rises above their desired income, they take other factors into account such as patient utility or their professional status (12-14). A much debated question in this field is deciding which factors determine the target income of physicians.

Searching relevant databases, we found very few studies on physicians' target income behavior (10-12, 15-19), and only one study specifically assessed the determinants of the target income of physicians (20). This study found that actual income, costs of medical practice, costs of studying medicine, discrimination and dissatisfaction, other preferences of the physician, and demographic factors can all influence income targets. However, this claim was not based on research, and in practice limited empirical analysis was done on a few demographic and practice variables.

Yet, a key conceptual question regarding this hypothesis (the question of how physicians set their income targets) remains unanswered(21). Therefore, this study aimed at answering this research question based on physicians' views using the principal component analysis (PCA) approach.

\section{Methods \\ Developing the instrument}

To understand how physicians set their income targets, a literature review and a small qualitative study were conducted. In the course of this literature review, the published papers related to the economic behavior of physicians, particularly studies focusing on target income behavior, were assessed. Based on the review findings, a semi-structured questionnaire was designed. Interviews were conducted with 10 general practitioners (GPs), and the main question was as follow: "What are the factors that determine your desired income level?" Participants' responses were analyzed to develop a quantitative questionnaire for assessing the views and attitudes of GPs concerning factors related to income targets. The developed self-administered questionnaire consisted of 24 questions, which were answered using the five-point Likert scale. To finalize these questions and assess the reliability and face validity of the questionnaire, a pilot study was conducted on 67 GPs. The pilot data were gathered in many cases using web-based and paper-based questionnaires. The estimated Cronbach's alpha coefficient was 0.7103 , which verified the internal-consistency reliability of the questionnaire. The content and face validity of the questionnaire were also confirmed by experts in the field of health economics and policy as well as GPs.

\section{Data collection}

Because there was no existing sampling frame for GPs in Iran that could be used for this study, we used 2 national congresses held by the Iranian Society of General Prac- titioners (ISGP). The Iranian Society of General practitioners (ISGP) is the conductor of retraining programs for GPs. It holds 4 seasonal congresses with retraining programs for GPs each year. GPs throughout the country participate in these congresses to receive the score allocated to retraining programs; therefore, it can be assumed that attendees will be representative of all Iranian GPs.

Participant sampling was conducted during the course of 2 congresses in the year 2015. Participants were selected using convenience sampling method during summer and autumn seasonal congress of ISGP in 2015. The questionnaires were distributed among 1142 GPs attending these congresses, and 599 completed questionnaires were collected at an appointed time (response rate $=52 \%$ ). In all $666(67+599)$ participants, observations were included in the statistical analysis.

\section{Statistical analysis}

PCA was applied to reduce the variables related to GPs' target income into a few main sets of principal components that accounted for most of the variance.

The PCA technique is based on correlations between variables; at first, PCA was applied to the variables based on the correlation matrix of the variables. Variables that had a correlation level lower than 0.3 were excluded from PCA. To check sample adequacy for PCA, the KaiserMeyer-Olkin (KMO) and Bartlett's tests of sphericity (BTS) were used. Principal components were retained based on eigenvalues more than $1(22)$ and scree plot patterns. The rotated matrix was obtained using the orthogonal varimax method. Finally, principal components were obtained and interpreted based on the rotated component loadings and the internal consistency reliability (Cronbach's alpha coefficient) of the variables in each component. Statistical analysis was performed using STATA 12.

\section{Results}

About 54\% $(n=358)$ of GPs in the sample were male. The mean \pm SD age and the years of practice of participants were about $43 \pm 9$ years and $13 \pm 9$, respectively. About $55 \%$ $(n=369)$ of the GPs worked in a private setting, $25.33 \%$ $(\mathrm{n}=168)$ in a public setting, and others worked in both areas simultaneously.

Based on the correlation coefficient between the variables (higher than 0.3), 16 variables were used for PCA. Descriptive results of the included variables for PCA are presented in Table 1.

The result of the KMO measure of sampling adequacy (0.657) revealed an adequate number of items for each component. Also, the results of BTS $(809.05, \mathrm{P}<0.001)$ showed a significant correlation between variables, and thus the data were suitable for PCA.

Table 2 demonstrates eigenvalues, the percentage of explained variance by components, and the cumulative share of explained variance. Based on the table, 6 components had eigenvalues greater than one. As demonstrated in Fig. 1, similar to eigenvalues, 6 components were retained according to where the slope of the scree plot levels off. These components accounted for $65.19 \%$ of the total vari- 


\begin{tabular}{|c|c|c|c|c|c|}
\hline \multirow[b]{2}{*}{ Variable } & \multicolumn{5}{|c|}{ Category } \\
\hline & Very low & Low & Medium & High & Very high \\
\hline Q1: Perception of income level relative to income of specialists & $307(48)$ & $232(36.2)$ & $98(15.3)$ & $3(0.5)$ & 0 \\
\hline Q2: Perception of income level relative to income of other GPs & $54(8.4)$ & $152(23.7)$ & $400(62.3)$ & $33(5.1)$ & $3(0.5)$ \\
\hline Q3: Perception of income level relative to income of foreign GPs & $324(53.1)$ & $205(33.6)$ & $75(12.3)$ & $6(1)$ & 1 \\
\hline Q4: Society's economic expectations & $2(0.3)$ & $28(4.4)$ & $132(20.6)$ & $302(47)$ & $178(27.7)$ \\
\hline Q5: Family's economic expectations & $2(0.3)$ & $40(6.2)$ & $206(32.1)$ & $263(41)$ & $131(20.4)$ \\
\hline Q6: Self economic expectation & $10(1.6)$ & $55(8.5)$ & $306(47.5)$ & $215(33.4)$ & $58(9)$ \\
\hline Q7: Importance of quality in service provision & $2(0.3)$ & $1(0.2)$ & $28(4.4)$ & $263(41)$ & $348(54.2)$ \\
\hline Q8: Importance of patients' satisfaction & 0 & $2(0.3)$ & $36(5.6)$ & $235(36.4)$ & $372(57.7)$ \\
\hline Q9: Perception of patient satisfaction from provided services & 0 & $3(0.5)$ & $123(19.7)$ & $409(65.4)$ & $90(14.4)$ \\
\hline Q10: Self-referral & $149(52.3)$ & $77(27)$ & $45(15.8)$ & $10(3.5)$ & $4(1.4)$ \\
\hline Q11: Advertisement & $396(62.2)$ & $136(21.3)$ & $90(14.1)$ & $15(2.4)$ & 0 \\
\hline Q12: Economic status of the population nearby the GPs habitation place & $21(3.2)$ & $166(25.5)$ & $271(41.5)$ & $166(25.5)$ & $28(4.3)$ \\
\hline Q13: Perception of self-economic status & $112(17.1)$ & $372(46.9)$ & $160(24.5)$ & $8(1.2)$ & $2(0.3)$ \\
\hline Q14: Economic status of the population near the GPs practice place & $40(6)$ & $234(35.4)$ & $266(40.2)$ & $110(16.7)$ & $11(1.7)$ \\
\hline Q15: Father's education level & $55(8.4)$ & $121(18.4)$ & $91(13.9)$ & $147(22.4)$ & $242(36.9)$ \\
\hline Q16: Perception of father's economic status & $26(4)$ & $92(14)$ & $351(53.6)$ & $161(24.6)$ & $25(3.8)$ \\
\hline
\end{tabular}

Table 2. Eigenvalues and explained variance by components

\begin{tabular}{|c|c|c|c|}
\hline Components & Eigenvalues & Proportion ( $\%$ of variance) & Cumulative (\%) \\
\hline $\mathrm{C} 1$ & 2.6590 & 16.62 & 16.62 \\
\hline $\mathrm{C} 2$ & 2.4304 & 15.19 & 31.81 \\
\hline $\mathrm{C} 3$ & 1.7065 & 10.67 & 42.47 \\
\hline $\mathrm{C} 4$ & 1.3070 & 8.17 & 50.64 \\
\hline $\mathrm{C} 5$ & 1.2178 & 7.61 & 58.26 \\
\hline C6 & 1.1088 & 6.93 & 65.19 \\
\hline $\mathrm{C} 7$ & 0.8430 & 5.27 & 70.46 \\
\hline $\mathrm{C} 8$ & 0.8041 & 5.03 & 75.48 \\
\hline $\mathrm{C} 9$ & 0.8041 & 4.34 & 79.82 \\
\hline $\mathrm{C} 10$ & 0.5877 & 3.67 & 83.50 \\
\hline $\mathrm{C} 11$ & 0.5429 & 3.39 & 86.89 \\
\hline $\mathrm{C} 12$ & 0.4849 & 3.03 & 89.92 \\
\hline $\mathrm{C} 13$ & 0.4664 & 2.92 & 92.84 \\
\hline $\mathrm{C} 14$ & 0.4527 & 2.83 & 95.66 \\
\hline $\mathrm{C} 15$ & 0.3785 & 2.37 & 98.03 \\
\hline $\mathrm{C} 16$ & 0.3151 & 1.97 & 100 \\
\hline
\end{tabular}

Bold font shows components with eigenvalues greater than one

ance.

The final results of PCA are demonstrated in Table 3. In the rotated component matrix, loading values greater than 0.45 are shown in bold, and those below 0.2 are left blank.

The fifth and sixth components had very low internal consistency (Cronbach's alpha $=0.5$ ), therefore, these components were excluded from the discussion and from further consideration.

The components were specified based on the components loadings of the main variables (bold font).

Components 1 to 4 were labeled "perceived comparative

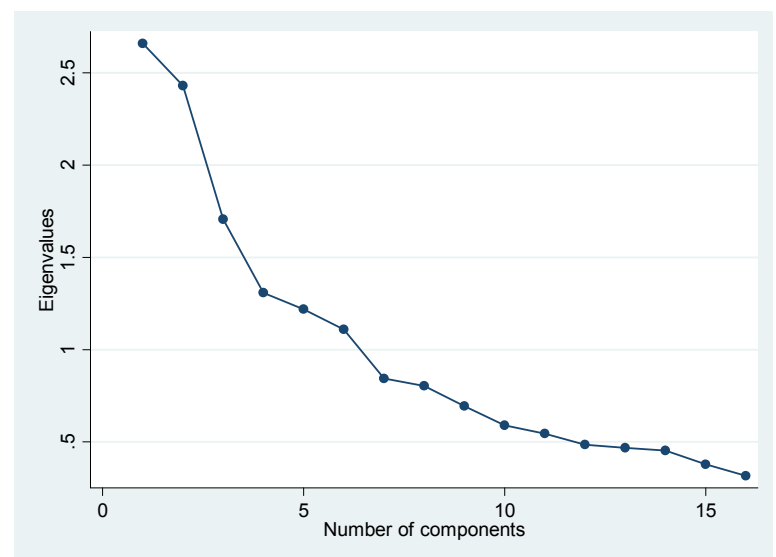

Fig. 1. Scree plot of eigenvalues income", "importance of responsiveness to patients", "perceived socioeconomic status", and "economic expectations", respectively.

\section{Discussion}

This study used data reduction and subsequent classification of the variables associated with GPs' views on factors affecting their income targets.

As mentioned in the results, there are 6 components that were retained based on the outputs from the PCA. However, the 4 reliable components based on Cronbach's alpha coefficient were named and assessed. The number of items in each component was limited (from 2 to 4 items), and this might have led to an underestimation of the Cronbach's alpha coefficient (23). Also, based on the evidence of prior research studies in which the cut-off value of Cronbach's alpha was considered $0.6,(24,25)$, we chose 0.6 as the cut-off value for Cronbach's alpha. Therefore, based on this cut-off value $(0.6)$, the internal consistency of Components 1 to 4 was confirmed.

The "perceived comparative income" (Cronbach's alpha $=0.71$ ) was the main component, accounting for more than $16 \%$ of the total variance. It consists of 3 variables as follow: "perception of income level relative to the income of specialists", "perception of income level relative to the income of other GPs", and "perception of income level relative to the income of foreign GPs". A quick glance at 


\begin{tabular}{|c|c|c|c|c|c|c|}
\hline \multirow[t]{2}{*}{ Variables } & \multicolumn{6}{|c|}{ Principal components } \\
\hline & $\mathrm{C} 1$ & $\mathrm{C} 2$ & $\mathrm{C} 3$ & $\mathrm{C} 4$ & $\mathrm{C} 5$ & C6 \\
\hline 1 & 0.7837 & & & & & \\
\hline 2 & 0.7904 & & & 0.2386 & & \\
\hline 3 & 0.6865 & & & & 0.2005 & \\
\hline 4 & & & & 0.8165 & & \\
\hline 5 & & & & 0.8072 & & \\
\hline 6 & & 0.3139 & & 0.4634 & & 0.2083 \\
\hline 7 & & 0.7212 & & & & \\
\hline 8 & & 0.7838 & & 0.2140 & & \\
\hline 9 & & 0.7550 & & & & \\
\hline 10 & & & & & & 0.7916 \\
\hline 11 & & & & & & 0.7869 \\
\hline 12 & & & 0.8932 & & & \\
\hline 13 & 0.6551 & & & & & \\
\hline 14 & & & 0.8852 & & & \\
\hline 15 & & & & & 0.8358 & \\
\hline 16 & & & & & 0.8061 & \\
\hline Cronbach's alpha & 0.71 & 0.67 & 0.74 & 0.67 & 0.51 & 0.50 \\
\hline
\end{tabular}

these 3 items brings to mind that they are all slight variations of a single theme and that is of a GPs perception of his/her income level relative to that of other physicians. Received salary, compared with that of other people, is one of the variables important to physician satisfaction (26) as well as a physician's chosen specialty (27). According to (20) physicians, dissatisfaction and discrimination are also factors influencing income targets.

The "importance of responsiveness to patients" component (Cronbach's alpha $=0.67$ ) as the second main component includes 3 variables: "the importance of quality in service provision", "the importance of patients' satisfaction", and "perception of patient satisfaction from provided services". It contributes to about $15 \%$ of explained the variance, showing the role of patients and responsiveness to them in a physician's economic behavior.

The third component that contributes to about $11 \%$ of the explained variance was "perceived socioeconomic status" component (Cronbach's alpha $=0.74$ ). It includes the "economic status of the population near the GP's habitation place, and the "economic status of the population near the GP's practice place" variables.

The "economic expectations" component (Cronbach's alpha $=0.67)$ consists of 3 variables as follow: "society's economic expectations", "family's economic expectations", and "self- economic expectation" items. This component explains about $8 \%$ of the total variance. Target income can be affected by the society, family, and the individual's economic expectations such as driving a luxury car or living in a large house.

Our study had some limitations. Our data collection process was not random. However, our main goal in the present study was to develop an instrument, so the generalizability of the findings was not that important. Furthermore, because there are few studies related to the economic behavior of physicians, the related literature was limited, which affected the maturity of our discussion.

The developed instrument and current findings may help researchers in assessing the target-income-based behavior of GPs. However, to improve the instrument and better understand its limitations, it should be tested empirically with additional research.

Further econometric studies should be conducted to assess how well these components and items explain target income variations in practice.

\section{Conclusion}

The questionnaire on factors affecting GPs' income targets was developed based on the views of GPs themselves. Based on PCA, 4 reliable principal components were used to classify the factors determining GPs' income targets.

Research related to the target-income-based behavior of physicians can benefit from our developed questionnaire and the main extracted principal components to better understand how GPs set their target income.

\section{Acknowledgements}

This project was conducted with the financial support of Tehran University of Medical Sciences. We also thank the Board of Directors of the ISGP for their support in the data gathering process during the 2 congresses.

\section{Conflict of Interests}

The authors declare that they have no competing interests.

\section{References}

1. Folland S, Goodman AC, Stano M. The economics of health and health care: Pearson Prentice Hall Upper Saddle River, NJ; 2007.

2. Preker AS. Public ends, private means: strategic purchasing of health services: World Bank Publications; 2007.

3. McGuire TG. Physician agency. Handbook of health economics. 2000;1:461-536.

4. Sloan FA. Physician fee inflation: Evidence from the late 1960s. The Role of Health Insurance in the Health Services Sector: NBER; 1976. p. 321-62.

5. Baumol WJ. Price controls for medical services and the medical needs of the nation's elderly (second of two parts). Connecticut medicine. 1988;52(9):542.

6. Arrow KJ. Uncertainty and the welfare economics of medical care. Am Econ Rev. 1963;53(5):941-73.

7. Evans RG. Supplier-induced demand: some empirical evidence and 
implications. The economics of health and medical care. 1974;6:162-73.

8. Newhouse JP. A model of physician pricing. South Econ J 1970:174-83.

9. Rice TH. The impact of changing Medicare reimbursement rates on physician-induced demand. Med care. 1983;21(8):803-15.

10. Sweeney GH. The Market for Physicians' Services: Theoretical Implications and an Empirical Test of the Target Income Hypothesis. South Econ J. 1982;48(3).

11. Rizzo JA, Blumenthal D. Is the target income hypothesis an economic heresy? Med Care Res Rev. 1996;53(3):243-66.

12. Rizzo JA, Zeckhauser RJ. Reference incomes, loss aversion, and physician behavior. Rev Econ Stat. 2003;85(4):909-22.

13. Feldstein MS. The rising price of physicians' services. Rev Econ Stat. 1970;52(2):121-33.

14. Thornton J, Eakin BK. The utility-maximizing self-employed physician. J Hum Resour. 1997:98-128.

15. Contandriopoulos D, Perroux M. Fee Increases and Target Income Hypothesis: Data from Quebec on Physicians' Compensation and Service Volumes. Healthc Policy. 2013;9(2):30-5.

16. Kantarevic J, Kralj B, Weinkauf D. Income effects and physician labour supply: evidence from the threshold system in Ontario. Can J Econ. 2008;41(4):1262-84

17. Rizzo JA, Blumenthal D. Physician labor supply: Do income effects matter? J Health Econ. 1994;13(4):433-53.

18. Rizzo JA, Zeckhauser RJ. Pushing incomes to reference points: Why do male doctors earn more? J Econ Behav Organ. 2007;63(3):51436.

19. Winney WO. Target Income Hypothesis: A Study of Cardiology Compensation: Medical University of South Carolina; 2010.

20. Rizzo JA, Blumenthal D. Physician income targets: new evidence on an old controversy. Inquiry. 1993;31(4):394-404.

21. McGuire TG, Pauly MV. Physician response to fee changes with multiple payers. J Health Econ. 1991;10(4):385-410.

22. Tzeng OC. On reliability and number of principal components: Joinder with Cliff and Kaiser. Percept Mot Skills. 1992;75(3):929-30.

23. Tavakol M, Dennick R. Making sense of Cronbach's alpha. Int J Med Educ. 2011;2:53.

24. Verbeke W, Vackier I. Individual determinants of fish consumption: application of the theory of planned behaviour. Appetite. 2005:44(1):67-82.

25. Malloy-Diniz LF, Paula JJd, Vasconcelos AG, Almondes KMd, Pessoa R, Faria L, et al. Normative data of the Barratt Impulsiveness Scale 11 (BIS-11) for Brazilian adults. Revista Brasileira de Psiquiatria. 2015;37(3):245-8.

26. McMurray JE, Williams E, Schwartz MD, Douglas J, Van Kirk J, Konrad TR, et al. Physician job satisfaction. J Gen Intern Med. 1997;12(11):711-4.

27. Kiker B, Zeh M. Relative income expectations, expected malpractice premium costs, and other determinants of physician specialty choice. J Health Soc Behav. 1998:152-67. 